\title{
Long Ago and Far Away: Preservice Teachers' (Mis)Conceptions Surrounding Racism
}

\author{
Melissa Beth Wilson \\ Leeds Trinity University \\ U. K. \\ Tracey Kumar \\ Southeastern Louisiana University \\ U. S. A.
}

ABSTRACT: This study examines a large data set of preservice teachers' definitions of racism at the beginning and at the end of a teacher training program in the Southeastern United States. Using the methodology of Critical Content Analysis that is grounded in Critical Race Theory, the authors found that the majority of the definitions illustrate a removed, passive, and oldfashioned conception of racism indicative of reluctance on the part of both preservice teachers and their university trainers to grapple with the historical and cultural context of the geographical area as well as to acknowledge the systemic nature of racism.

KEYWORDS: critical race theory, critical content analysis, teacher education, racism, preservice teacher

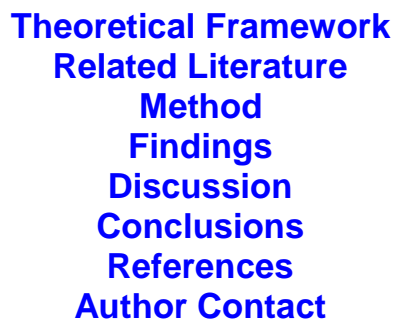

We have made enormous progress in teaching everyone that racism is bad. Where we seem to have dropped the ball... is in teaching people what racism actually IS. -Jon Stewart, Comedian-

The above quote points to a critical issue within teacher training programs in the United States. While it is clear that we, teachers and teacher trainers, are not doing enough to address racism in our educational institutions, it is equally clear that we are not sure exactly what to do about this problem or, in fact, what racism actually is. Research has demonstrated that many teachers lack a 
comprehensive understanding of racism (Modica, 2012; Sleeter, 1995; Young, 2011). Specifically, White teachers view racism as an individual phenomenon, rather than an institutional actuality (Modica, 2012; Carignan, Sanders, \& Pouravood, 2005). Because of these (mis)understandings, some White teachers assume that the United States affords equal opportunities to members of all racial and ethnic groups and that discussions of racism are no longer relevant (Sleeter, 1995; Picower, 2009). At the same time, many White teachers espouse "colorblind" ideologies; in other words, they circumvent issues of racism by claiming that all children are equal as they only see the child and not the child's color (Bonilla-Silva, 2013; Bonilla-Silva \& Dietrich, 2011; Bonilla-Silva \& Forman, 2000). Many White teachers also possess unexamined deficit views of students from diverse racial and ethnic backgrounds having tacit beliefs that diverse students are inferior to students from their own backgrounds (Allen, 2013).

White teachers' misunderstandings of racism, coupled with their concomitant failure to explore racial injustices particularly within the context of P12 education, have a devastating impact on the outcomes of students from diverse racial and ethnic backgrounds (Goldhaber \& Hansen, 2010; Howard \& Navarro, 2016; Tenenbaum \& Ruck, 2007; Sleeter, 1995). As an illustration of this, research has shown that students of color are punished, suspended, and expelled at a rate three times as high as White students and are often placed in lower-level classes and/or referred for special education services (Civil Rights Data Collection, 2016). These injustices persist despite years of calls for multicultural/antiracist/tolerance teaching (Durden, McDunn, \& Truscott, 2016), 27 years after Mclntosh (1988) published White Privilege: Unpacking the Invisible Knapsack and eleven years after Kozol (2005) wrote:

Schools that were already deeply segregated twenty-five or thirty years ago are no less segregated now, while thousands of other schools around the country that had been integrated either voluntarily or by the force of law have since been rapidly resegregating. (p. 42).

To improve the outcomes of students from diverse racial and ethnic backgrounds, many teacher training programs have begun to intensify their efforts to educate preservice teachers (PSTs) on issues such as diversity and multiculturalism. For that purpose, many programs have begun requiring PSTs to take diversity-related courses (Chisholm, 1993; VanDeventer Iverson, 2007; Watson, 2012). Furthermore, to prepare PSTs to act as change agents and interrupt discourses of inequality, some teacher trainers (TTs) have also begun to incorporate critical, culturally relevant, and anti-racist pedagogies into their teaching (Durden et al., 2016; Garmon, 2004). Apart from coursework, many programs have instituted fieldwork and professional development that expose mostly White and mostly female PSTs to "others" as a means of fostering intercultural competencies (VanDeventer Iverson, 2007; Carignan et al., 2005).

Such issues are particularly salient at ZSU (pseudonym for the university in this study), where the vast majority of faculty and students are White. In the years we researched, 2011-12 and 2012-13, over $90 \%$ of PSTs and TTs identified as White. The university's location in the Southeastern United States has a 
cultural/historical milieu of slavery and of de jure and de facto segregation. Therefore, in recent years, ZSU has placed increasing emphasis on helping the overwhelmingly White PSTs begin to understand racism and other related forms of injustice. To this end, ZSU, like many universities, has implemented diversityrelated coursework, field experiences in diverse school settings, and workshops on race and other relevant issues. Nonetheless, as Hoyt (2012) explains, "The idea and action of racism is not easy to teach or learn in a simple and straightforward manner" (p. 225).

Thus, considering recent changes to ZSU's teacher training programs, we thought it would be helpful to examine how PSTs conceptualize racism. To this end, we examined and analyzed their responses to the question, "What is racism?" By doing this we gained insight into what the PSTs think (and do not think) about racism. The question is seemingly simple; however, the answers are nebulous, imbued with the "unsurety" of TTs and PSTs and the tacit theories that guide socalled "common sense" thinking (Carignan et al., 2005; Cross, 2005). Influenced by Critical Race Theory, we sought to determine whether PSTs conceptualized racism the "old way" (between people) or the "new way" (within institutions) and to use these findings to improve our own practice and guide social justice practices in schools of education in the United States and elsewhere (Cross, 2005).

\section{Theoretical Framework}

Critical Race Theory (CRT) emerged from critical legal scholarship at the culmination of the Civil Rights Movement and evolved as a result of several key events, including boycotts of classes at law schools throughout the United States, a meeting of several influential critical race scholars, and the publication of a special edition of the Civil Rights/Civil Liberties Law Review (Taylor, 2009). Through their work, critical race scholars identified at least four tenets central to CRT: (a) although racism is a "normal fact of daily life in U.S. society" (Taylor, 2009 , p. 4), it typically goes unnoticed by those who do not experience it; (b) in accordance with Bell's theory of interest convergence, "Racial equality will be accommodated only when it converges with the interests of whites" (Bell, 2009, p. 76); (c) the narratives of those who experience oppression can be instrumental in clarifying the nature of racism; and (d) instances of oppression can only be understood when they are situated within the appropriate historical context (Taylor, 2009).

In accordance with these tenets, education scholars assert that racism is woven into the fabric of education in the United States (Solòrzano \& Yosso, 2001). Consequently, CRT in education works to "identify, analyze, and transform those aspects of education that maintain dominant and subordinate positions in and out of the classroom" (Solòrzano \& Yosso, 2001, p. 25). To fulfill that aim, education scholars utilize insights and methods from a variety of disciplines and examine the narratives of those who have experienced racism and other forms of oppression. For example, using CRT, education scholars have investigated a variety of 
phenomena, including school-based microaggressions (subtle discriminatory actions or statements) against parents and children of African-American descent (Allen, 2013), and the nature of race consciousness among White educators (Young, 2011). Therefore, using CRT as a theoretical framework, the present study examined how PSTs conceptualized racism through their definitions of it.

\section{Related Literature}

While studies have yet to examine how White PSTs define racism, there has been a surge of work pertaining to CRT within education. Findings within this literature indicate that White educators, both preservice and inservice, view racism as residing in individuals and not as an institutional problem (Garrett \& Segall, 2013; Howard \& Navarro, 2016; Young, 2011). This (mis)understanding causes teachers to look at racism as belonging to someone else and therefore not an issue they need to own. This is also true for educators who "teach tolerance" and position themselves as part of the solution. Again, this thinking posits that racism resides in, and can be fought in, the individual person, classroom, school, etc. (LadsonBillings, 2009; McDonough, 2009).

Another theme in recent literature is that PSTs neither know, nor want to know, about racism (Galman, Pica-Smith, \& Rosenberger, 2010; Garrett \& Segall, 2013; Leonardo, 2009; McDonough, 2009). This can be explained by a failure to address these topics in educational settings or by the idea that White PSTs (the vast majority of education majors in the USA), because of their privilege, have no need to think about something that does not directly affect them, their families, or their neighborhoods (Leonard \& Leonard, 2006; Milner, 2008). Many PSTs come to training programs with a resistance to dealing with race and prefer to take a "colorblind" approach, as this is easier (Garrett \& Segall, 2013; McDonough 2009). Confronting racism can be difficult for White PSTs when they are told they are a part of the problem and that they perpetuate the problem every day (Galman et al., 2010). Flynn (2015) coined this reluctance "white fatigue," positing that White PSTs understand, on some level, their part in racism but feel helpless and victimized.

Recent scholarship has also addressed the seemingly obvious concept of "Whiteness." While there has been much emphasis on examining people of color, White people, as the unmarked category, historically have borne little scrutiny, to the detriment of the fight for social justice (Ladson-Billings, 2009; Picower, 2009). Dyer (1997) asserts: "As long as race is something only applied to non-white peoples, as long as white people are not racially seen and named, they/we function as the human norm" (p.1). Thus, to actively examine Whiteness and its privileges is to take away its very "normalcy" and therefore to disrupt a racist discourse. It is salient to distinguish the term "White people" from the term "Whiteness." The former is a socially constructed category while the latter is a racial discourse (Gillborn, 2009). One must name something to discuss it, and by naming White as a race, we/they are included in conversation and are not simply discussing racism from the outside (Picower, 2009; Watson, 2012). 
This discussion depends on where individuals are in their understandings of racism and their role in it. Young (2011) writes that teachers espouse four types or "personae" of racism. Educators in the first category view racism as residing in people's actions, removed from "us" and resting squarely with "them." Those in the second category also view racism as residing in individuals but recognize that racism exists on a spectrum, ranging from subtle to obvious. Those in the third category strive to fight racism without realizing their own complicity or the privilege of their actions, while those in the fourth category recognize their own subtle racism while still viewing the issue as residing in people. None of the categories represents racism as an institutional problem in which we are all willing or unwilling conspirators.

According to Picower (2009), morphing race and ethnicity and referencing ahistorical mythology are the barriers that must be overcome for White people to see racism as part of American life and something that they reconstitute daily (pp. 207-208). Garrett and Segall (2013) add that White students are not "ignorant" about racial issues and that TTs need to hold them accountable for their actual knowledge and not allow a failure of seeing injustice. The failure to see racism as institutional aligns with the idea of "old racism" versus "new racism" and is another common theme within the literature (Cross, 2005; Picower, 2009; Virtanen \& Huddy, 1998). According to Virtanen and Huddy (1998), old racism is overt and clear while new racism is covert and symbolic. Cross (2005) defines old racism as "prejudice and supremacy, visible, and applied to the individual," while new racism is defined by "power and domination, visibility, and applied to social bodies; in other words, institutionalized" (p. 267).

A recommendation shared by some articles is that all teachers-preservice, inservice, and teacher trainers-must be taught not only how but also why to work toward social justice (Carignan et al., 2005; Galman et al., 2010; McDonough, 2009; Modica, 2012). Thus, TTs must create classrooms where difficult subjects can be discussed, in other words, "spaces where Whiteness can be named and interrogated" (Galman et al., p. 229). This speaks to the responsibility of TTs, who, like PSTs, are overwhelmingly White, middle class, and female. Moreover, we cannot change (or teach) what we do not understand. Recent research has found that White PSTs do not participate in difficult racial discussions and neither do their instructors (Galman et al., 2010; Howard \& Navarro, 2016; Picower, 2009). In fact, TTs silence or "sanitize" race talk and circumvent discussions of differences among groups (Cross, 2005; Pimentel, 2010). To combat this, recent research suggests that TTs must aggressively challenge themselves and their tacit theories while, at the same time, working tenderly with others (Galman et al., 2010). A starting point seems to be the examination of PSTs' (mis)conceptions surrounding racism.

\section{Method}

To examine these (mis)conceptions, we posed three research questions: 
1. How do PSTs define racism?

2. How do these definitions speak to how PSTs construct the idea(s) of racism?

3. What, if any, changes occur between the first definition written at the beginning of the program and the second definition written at the end?

We attempted to answer our research questions through this study conducted in the college of education at a mid-size public university in the Southeastern United States. The university is known for its teacher training programs, and graduates are typically recruited by school districts throughout the region. As a result, the college serves as one of the region's foremost contributors of newly certified teachers. For these reasons, many students enroll in the university with the intention of pursuing a degree in education. Furthermore, the population served by the college is overwhelmingly White and female. For example, of the PSTs who graduated during the 2011-2012 and 2012-2013 academic years, 91.1\% identified as White, $5.3 \%$ as African-American, and $1.3 \%$ as Hispanic, Asian, or two or more races combined (see Table 1). Of those same PSTs, $88 \%$ were identified as female and $12 \%$ as male. Therefore, the population served by the college is representative of the homogeneity of the U.S. teaching force. The faculty also reflects this, with one member who identifies as a cis-gender male and one female professor who identifies as African-American, with the rest identifying as White females.

Table 1. The Racial Breakdown of Respondents in the Data Set.

\begin{tabular}{lcc}
\hline \multirow{2}{*}{ ZSU's Racial Categories } & \multicolumn{2}{c}{ School year } \\
\cline { 2 - 3 } & $\mathbf{2 0 1 1 - 2 0 1 2}$ & $\mathbf{2 0 1 2 - 2 0 1 3}$ \\
\hline Asian & 0 & 1 \\
Black & 9 & 18 \\
Hispanic & 1 & 2 \\
White & 210 & 252 \\
Two or more races & 1 & 1 \\
Not reported & 7 & 5 \\
\hline Total number of students & 228 & 279 \\
\hline
\end{tabular}

Over the past few years, a major focus of the college has been attending to issues of diversity both in the student population and in the curriculum. As a result, PSTs in all programs must take a one-credit-hour diversity course, which highlights issues relevant to supporting the achievement of students from multicultural backgrounds. Throughout the course, PSTs are asked to reflect on their own backgrounds and experiences and to examine how those backgrounds and experiences influence their understanding of diverse learners. PSTs are also asked to explore classroom-based scenarios, which reflect issues of diversity such as race and racism. Apart from this course, the college has also begun to offer relevant professional development workshops; increased opportunities for PSTs to interact with diverse students, faculty, and community members; and implemented initiatives aimed at recruiting and retaining PSTs from diverse backgrounds. 


\section{Data Source}

To examine PSTs' understandings of racism, this study analyzed 796 individual responses to the prompt "define racism," by PSTs enrolled in initial certification programs within the college of education. The data set was extant as these responses were written as a requirement for PSTs' electronic portfolios, which they begin to assemble upon entry into a teacher-training program and submit upon completion of student teaching or a comparable internship program. The portfolios serve as a tool for collecting evidence pertaining to coursework, field experiences, and professional development. Prior to collection, PSTs were made aware that the data in their portfolios would be used for research and/or program development.

This evidence is used to evaluate both individual PSTs and various teachertraining programs and to make changes, which are conducive to enhancing the preparation of all PSTs. For our study, which had Institutional Research Board approval, the 796 responses were extracted from electronic portfolios that were submitted for review during the 2011-12 and 2012-13 academic years. Prior to extraction, the responses were stripped of identifiers including names and identification numbers. Of the 796 responses, $324(41 \%)$ were extracted from the portfolios of PSTs in the initial stages of their program, and $478(59 \%)$ were extracted from the portfolios of PSTs who were completing their student teaching or internship experience.

Having expunged the respondents' identifiers, we were unable to compare and contrast individual changes from the beginning to the end of the program. Instead, we compared and contrasted the entire corpus and found almost no differences between the pre and post responses. Furthermore, a cursory review revealed that many PSTs put minimal effort into composing their responses, as the majority of responses were brief and many contained spelling and grammatical errors. In addition, most of the responses failed to consider theoretical or researchbased understandings of racism. The lack of identifiers also made it impossible for us to match the race of individuals to their responses. We looked at the data set as a whole, and knowing the racial make-up of the groups we inferred that over $90 \%$ of the data were from students who identified as White.

\section{Data Analysis}

To analyze PSTs' definitions of racism, we employed Critical Content Analysis:

.... hybrid methodology, which involves close reading of small amounts of text that are interpreted by the analyst and then contextualized in new narratives... this is a hermeneutic, reader response oriented research stance that can be critical as well. What makes the study 'critical' is not the 
methodology but the framework used to think within, through, and beyond the text. (Beach et al., 2009, pp. 2-3)

Responses to the prompt "define racism" served as the unit of analysis for this study. To begin the process, we read the entire data set individually, noting our own ideas with respect to codes. Then, we came together and shared our ideas, built consensus regarding an initial set of codes, and created a corresponding codebook (Neuendorf, 2016). Next, we worked collaboratively to code the first half of the data, modifying the codes and codebook throughout the process. Finally, we each coded half of the remaining data before coming together to verify inter-rater reliability. For that purpose, we checked for consensus on every fourth response within the individually coded data. This kind of analysis is concerned with generating new knowledge and looks for anomalies while the researchers are using induction and deduction (Hoffman, Wilson, Martinez, \& Sailors, 2011).

\section{Researcher Positionality}

Like most teacher educators in the USA, we also identify as White cisgender women. We paired up for this project due to common interests and asked the faculty to join, with no one responding. From our training, education, and research we have come to realize that our Whiteness is problematic as we are imbued with privilege and help to recreate institutional racism daily. Nevertheless, like many scholars who identity as White and write about racism and education (DiAngelo, 2016; Lensmire, 2012), we aspire "to move white educators forward...in a way that disrupts whiteness rather than masking or ignoring the power of whiteness" (Fasching-Varner, 2013, p. 1); this movement includes us. Doing so is not always easy, because our positionality, who we are, allows us "to see and understand some social dynamics while obscuring others" (DiAngelo, 2016, p.81). However, we are committed to social justice, and like Lensmire (2012) we are aware of the unsolvable issues inherent with being a part of the problem we hope to solve.

\section{Findings}

While the data set has 796 responses to the question, "What is racism?" the majority of the responses were generally very similar, as most of the data, when analyzed, may be read as rote answers. This conformity suggests that little individual thought went into this work, and students may have just repeated what they believe to be the "right answer." However, while the data set is rather uniform, there are subtle, nuanced differences that emerged as we recursively analyzed the responses. Below, we discuss in detail the three most coded combinations or themes. 


\section{Overt Actions with a Reason}

The theme that appeared most frequently in the data, overt actions with a reason $(n=82)$, conceptualized racism as mistreatment or discrimination against individuals or groups of color, due to race or other related attributes. Based on this conceptualization, overt discriminatory behaviors comprise one of the key elements of racism. As such, responses pertaining to this conceptualization frequently addressed the treatment of people of color. To illustrate, one respondent defined racism as "the poor treatment or isolating of a certain group of people because of their race," and another defined it as "the act of treating someone differently due to their ethnicity/race." Additionally, respondents highlighted overt discriminatory behaviors by referencing phenomena such as "discrimination," "violence," and "abuse." For example, one respondent defined racism as "the unfair practice of discriminating against an individual based on that person's race," while another defined it as "poor treatment or violence against people because of their race." Therefore, within this theme, respondents identified overt discriminatory behaviors, ranging in intensity from mild (e.g., "differential treatment") to severe (e.g., "violence"), as a key component of racism.

Furthermore, these overt discriminatory behaviors appeared to be directly attributable to the racial status of the victim(s). As illustrated by the above examples, race was frequently cited as the basis for overt discriminatory behaviors. Apart from race, respondents cited attributes that are commonly conflated with race, such as skin color and ethnicity. For example, one respondent defined racism as "discriminating due to one's race or skin color," while another defined it as "poor treatment or unfairness against people due to their race or ethnicity." In addition, the respondents also included attributes such as culture, religion, and national origin in their definitions. For example, one respondent defined racism as "the mistreatment or abuse of people because of the difference in nationality, color, or religion." Similarly, another respondent defined it as "maltreatment of a person or group based on their race; this can be their skin color, ethnic roots, traditions, and culture."

\section{Overt or Covert Actions with No Reason}

The theme that was the second most common $(n=49)$ conceptualizes racism as overt manifestations (e.g., mistreatment, discrimination), as well as the thoughts, beliefs, and feelings that underlie those manifestations (i.e., covert). Whereas overt manifestations consist of actions that can be seen by others, covert manifestations reside solely within the individual and, therefore, are invisible. As such, covert manifestations may reside in the cognitive domain (e.g., thinking, believing) or in the affective domain (e.g., feeling). To denote manifestations within the cognitive domain, respondents used terms such as "thinking" and "believing"; as one respondent wrote, racism is "having a thought or acting on a thought that 
targets a specific gender, race or ethnicity." Similarly, another defined it as "unjust and uneducated thoughts or comments that are towards another person(s)." However, to denote affective manifestations, respondents used feeling words such as "hatred" and "dislike." For example, one respondent defined racism as "hatred or intolerance toward another race or races," while another defined it as "showing dislike or hatred towards a race of people."

This construction of racism differs from the previous one in at least two ways. First, while the previous conceptualization was limited to overt manifestations of racism, this theme includes both covert (e.g., thoughts, feelings) and overt manifestations (e.g., comments, actions). Because this category acknowledges both seen and unseen elements, it is slightly more complex than the previous. Second, while responses associated with the previous combination made explicit the connection between racism and demographic characteristics such as such as race, ethnicity, and religion, these responses fail to identify the root cause of racism. Therefore, while the members of diverse racial, ethnic, and religious groups are identified as the targets of racism, these statuses are not explicitly identified as the cause. This could suggest that the respondent assumes that the reason, whether overt or covert in nature, is implicit in the definition; in other words, racism is actions toward "others" and no explanation is necessary.

\section{Thinking/Feeling Superior}

The third most frequent theme, thinking/feeling superior $(n=48)$, constructs racism as the thoughts, beliefs, and feelings that underlie attitudes toward others, based, in this case, on a racial hierarchy. This combination is the most nuanced as it includes responses that seem to reflect the tacit assumption that one's own race-which in this case, based on the demographics of the university, means White-is superior and other races are inferior. One example of this thinking is, "Racism is the belief that one's own ethnicity or race is superior to others; that races are not created equal." However, this assumption does not result in any outward manifestations of racism and therefore remains within the thoughts, beliefs, and feelings of the individual. This acknowledgment is seen in this particular response, "The belief that certain races are superior to others," which is seen in the data set in almost the same words in the majority of responses for this theme. Like the themes above, the definition is in the passive voice. No respondent claims to feel this way, and no actual perpetrator is named. For example, in the definition, "The thought that one race is better than the rest," no one is thinking that her race is better than the "rest" and no race is actually named, although signifiers may imply this missing information. For example, in this response, "A belief in the racial superiority of a particular race over another particular race," the "particulars" may set up a binary (as there seem to be only two choices) that could be read in the context of the Southeastern United States as the binary of White/Black. 


\section{Discussion}

Using the tenets of CRT (Taylor, 2009), the findings show that the everyday nature of racism in the United States remains unnoticed by the PSTs who are overwhelmingly White, as they do not experience it. Furthermore, because the respondents align themselves rigidly along "us" and "them" lines, there is no interest convergence to accommodate equality. Some of the (mis)conceptions surrounding racism may be that the teacher program lacks narratives of those who experience oppression situated within the appropriate historical context (Taylor, 2009). Other reasons for the (mis)conceptions could be that the PSTs are only offered one, one-credit course devoted to diversity. This may not be enough time to tackle these issues and may suggest the university's low commitment to both TTs and PSTs working toward a better understanding of race and education and of the institutional nature of racism.

\section{Between You and Me}

Overwhelmingly, the findings from this study suggest that respondents conceptualize racism as an individual phenomenon. Respondents not only situated racism within the thoughts, feelings, and actions of individuals, but also identified individual manifestations of racism ranging in intensity from mild (e.g., dislike, differential treatment) to severe (e.g., hatred, violence). This understanding of racism as an individual phenomenon, rather than an institutional or structural phenomenon, appears to align with the concept of old racism (Fiske, 1993; Virtanen \& Huddy, 1998). As Fiske (1993) explains, old racism is characterized by blatant, individual acts of discrimination, which are rooted in the inferiority of "nonwhites." However, as obvious discrimination has become increasingly unacceptable since the Civil Rights Movement, old racism has gradually given way to new racism, which is embedded into social institutions, remains largely invisible, and relies on elements such as power and privilege (Cross, 2005).

By conceptualizing racism solely as an individual phenomenon, respondents failed to acknowledge the institutional nature of racism and, therefore, new racism. This view precludes the idea of racism as an ideology: in other words, "A belief system and social discourse that is grounded in and explains social practice (Doane, 2003, p. 9).

However, this is not at all surprising, as previous studies have also identified educators' lack of awareness with regard to institutional and structural inequality (Modica, 2012; Young, 2011). To illustrate, Young (2011) found "disconcerting evidence of how persistently [educators] regarded racism as acts of individual pathology rather than as a systemic problem" (p. 1453). Similarly, Modica (2012) found that PSTs rejected views of racism that aligned with institutional and structural inequality, instead proffering views of racism that were suggestive of an individual phenomenon. Consequently, the findings from this study align with 
findings from previous research on educators' beliefs about racism (Watson, 2012; Young, 2011).

\section{Not Me (or You)}

The themes discussed above embody "removedness" from racism. No respondent includes herself in her answer: her own experiences, thoughts, or feelings. That the majority of responses were written in passive voice further buttresses this disassociation. There is no one actually "doing" the racism. An example of this is, "Racism is the mistreatment of someone based on their race." No one actually mistreats someone based on race. This passivity may be a symptom of White PSTs' reluctance to engage with issues of racism (Garrett \& Segall, 2013; Picower, 2009).

Another commonality within the data is that no group is explicitly identified as the target of racism. One may assume in the Southeastern United States that old racism would have been done by Whites to Blacks. However, only outliers actually ever name a race. Instead, to signify this, responders use the term "specific race" or "particular race" (and other such signifiers), leaving the reader to infer the intended meaning. An exemplar of this is, "Racism is usually defined as views, practices and actions reflecting the belief that humanity is divided into distinct biological groups called races and that members of a certain [italics added by authors] race share certain attributes which make that group as a whole less desirable, more desirable, inferior or superior." This is interesting as the PST mentions races and then homes in on a "certain race." Watson (2012) found in her study an analogous phenomenon, wherein teachers did not name races and instead referred to themselves and other Whites as "suburban" and their students as "urban." This is because, Watson reasons, "For these teachers, the words urban and suburban include race and class and convey the systems of meaning associated with skin color. Suburban becomes a proxy for white, while urban becomes a proxy for non-white" (p. 994).

The passivity within the answers may be attributed to how White people talk about racism in the United States. It is interesting that McIntosh (1988), the scholar who made the first arguments about White privilege, did so in a passive voice. Critiquing McIntosh's passivity, Leonardo (2009) writes, "White racist thoughts are disembodied, omnipresent but belonging to no one" (p. 267). On other words, these racist thoughts belong to some people somewhere but not to me/you/us. As such, racism in this view seems to be a misdeed for which there is nobody to blame. This thinking aligns with Young's first persona of racism, racism as acts of conscious perpetrators. Racism is in people's actions that are removed from us/we/me/l.

This "removedness" mirrors the disconnect between White people and their Whiteness (Solòrzano \& Yosso, 2001; Watson, 2012). Being White is the norm, something that requires no discussion as it is what is expected. This normalcy is 
comfortable as evidenced by the reactions of white PSTs when the reality of White privilege is offered as a discussion or concept to explore. For many PSTs, this concept is foreign and uncomfortable (Galman et al., 2010; Garmon, 2004). For scholars of CRT, this ignorance is more than just a passive deficit of knowledge; it is an active refusal to interact with the idea of racism as part of the structure of our society (Garrett \& Segall, 2013). To do so would mean including oneself as a part of the problem while simultaneously admitting that the problem is bigger than we are and cannot be resolved by being "nice to everyone" or by including books with African American characters in the classroom. This seems to signify the CRT tenet that racism is everywhere yet it goes unnoticed (consciously or unconsciously) by members of the dominant group. Racism is the normal state of things in the United States and, much like the evil perpetrated during the Holocaust, it has become "banal" (Arendt, 1963).

\section{So What?}

Lastly, there is no commentary that conveys a sense of social justice in these responses, as they are value-neutral. In other words, the PSTs do not make connections to themselves, their chosen profession, or their thoughts or feelings, nor do they judge racism as bad or good. This may be the failure of the teachertraining program that, like many others, claims to have a commitment to diversity and social justice; however, its poor record of recruiting faculty and students of color and its reliance on Eurocentric curricula seem to belie its "good intentions." This disconnect between words and deeds does not help to encourage or insist that TTs engage in the difficult work of developing "cultural consciousness, intercultural sensitivity, and a commitment to social justice" (Leonard \& Leonard, 2006, p. 34).

\section{Conclusion}

To harken back to our original research questions, we can conclude that the definition of racism for this group is one that is passive, removed, and steeped in old ways of thinking. These definitions may signal that the construction of racism is one that is uncomfortable due to the historical and sociological milieu of both the respondents and the geographical area. Moreover, because there was no perceptible change in the definitions we may conclude that what little the PSTs are learning in their teacher education program is not helping them to think differently.

These findings are not surprising given the racial imbalance in the setting for this study, where over $90 \%$ of PSTs and TTs are White. The positionality of this demographic would make it difficult to see institutional racism, as the clear majority of the people involved are not affected by inequities themselves (DiAngelo, 2016). This blind spot is exacerbated by the reluctance of TTs and PSTs to enter difficult discussions regarding race, which can be attributed to White fatigue (Flynn, 2015), 
White resistance (Garrett \& Segall, 2013), color blindness (Bonilla-Silva, 2013; Bonilla-Silva \& Dietrich, 2011), or ignorance of how to engage in this kind of dialogue (Galman et al., 2010).

These findings indicate a need to overcome the above issues by teaching both PSTs and TTs how to examine their own beliefs and positions to begin to make sense of racism and education (Fasching-Varner, 2013; Lensmire, 2012). This study also indicates the need to fill in the gaps in the literature in regard to how schools of education and their faculties can work towards social justice and equity in education by making diversity and anti-racism a larger part of the curriculum and by inviting faculty to engage in research that examines injustices.

\section{References}

Allen, Q. (2013). "They think minority means lesser than": Black middle-class sons and fathers resisting microaggressions in the school. Urban Education, 48(2), 171-197.

Arendt, H. (1963). Eichmann in Jerusalem. New York, NY: Viking Press.

Beach, R., Enciso, P., Harste, J., Jenkins, C., Raina, S. A., Rogers, R., et al. (2009). Exploring the "critical" in critical content analysis of children's literature. In R. T. Jiménez, M. K. Hundley, V. J. Risko, \& D. W. Rowe (Eds.), $58^{\text {th }}$ yearbook of the National Reading Conference (pp 129-143), Oak Creek, WI: National Reading Conference.

Bell, D. A. (2009). Just what is Critical Race Theory and what's it doing in a nice field like education? In E. Taylor; D. Gillborn \& G. Ladson-Billings (Eds.), Foundations of Critical Race theory in education (pp. 37-50). New York, NY: Routledge.

Bonilla-Silva, E. (2013). Racism without racists: Color-blind racism and the persistence of racial inequality in America. New York, NY: Rowman \& Littlefield Publishers.

Bonilla-Silva, E., \& Dietrich, D. (2011). The sweet enchantment of color-blind racism in Obamerica. The ANNALS of the American Academy of Political and Social Science, 634(1), 190-206.

Bonilla-Silva, E., \& Forman, T. A. (2000). "I am not a racist but..." Mapping white college students' racial ideology in the USA. Discourse \& Society, 11(1), 5085.

Carignan, N., Sanders, M., \& Pouravood, R. G. (2005). Racism and ethnocentrism: Social representations of preservice teachers in the context of multi- and intercultural education. International Journal of Qualitative Methods, 4(3), 1-17.

Chisholm, I. M. (1993). Preparing teachers for multicultural classrooms. The Journal of Educational Issues of Language Minority Students, 14, 43-68. 
Civil Rights Data Collection. (2016). A first look: Key data highlights on equity and opportunity gaps in our nation's public schools. Washington DC: U.S. Department of Education.

Cross, B. E. (2005). New racism, reformed teacher education, and the same ole' oppression. Journal of Educational Studies, 38(3), 263-274.

DiAngelo, R. (2016). What does it mean to be white? Developing white racial literacy. New York, NY: Peter Lang.

Doane, A. W. (2003). Contested terrain: Negotiating racial understandings in public discourse. Humanity \& Society 27(4), 554-575.

Durden, T., McMunn, C., \& Truscott, D. (2016). Race still matters: Preparing culturally relevant teachers. Race, Ethnicity and Education, 19(5), 10031024.

Dyer, R. (1997). White. London, United Kingdom: Routledge.

Fasching-Varner, K. (2013). Working through whiteness: Examining white racial identity and profession with pre-service teachers. London, United Kingdom: Lexington Books.

Fiske, J. (1993). Power plays power works. New York, NY: Verso.

Flynn, J. E. (2015). White fatigue: Naming the challenge in moving from an individual to a systemic understanding of racism. Multicultural Perspectives, 17(3), 115-124.

Galman, S., Pica-Smith, C., \& Rosenberger, C. (2010). Aggressive and tender navigations: Teacher educators confront whiteness in their practice. Journal of Teacher Education, 61(3), 225-236.

Garmon, M. A. (2004). Changing preservice teachers' attitudes/beliefs: What are the critical factors? Journal of Teacher Education, 55(3), 201-213.

Gillborn, D. (2009). Education policy as an act of white supremacy: Whiteness, critical race theory, and education reform. In E. Taylor, D. Gillborn, \& G. Ladson-Billings (Eds.), Foundations of Critical Race Theory in education (pp. 51-72). New York, NY: Routledge.

Garrett, H. J., \& Segall, A. (2013). (Re) considerations of ignorance and resistance in teacher education. Journal of Teacher Education, 64(4), 394-304.

Goldhaber, D., \& Hansen, M. (2010). Race, gender, and teacher testing: How informative a tool is teacher licensure testing? American Educational Research Journal, 47(1), 2018- 251.

Hoffman, J. V., Wilson, M., Martinez, R., \& Sailors, M. (2011). Content analysis in literacy research: The past, present and future. In N. K. Duke \& M. H. Mallette (Eds.), Literacy research methodologies, (2 ${ }^{\text {nd }}$ ed.). New York, NY: Gilford.

Howard, T. C., \& Navarro, O. (2016). Critical race theory 20 years later: Where do we go from here? Urban Education, 51(3), 253-273. 
Hoyt, C. (2012). The pedagogy of the meaning of racism: Reconciling a discordant discourse. Social Work, 57(3), 225-234.

Kozol, J. (2005) "Still separate, still unequal: America's educational apartheid," Harper's Magazine, 311(1864), 41-54.

Ladson-Billings, G. (2009). Just what is Critical Race Theory and what's it doing in a nice field like education? In E. Taylor; D. Gillborn, \& G. Ladson-Billings (Eds.), Foundations of Critical Race Theory in education (pp. 17-36). New York, NY: Routledge.

Leonard, P., \& Leonard, L. (2006). Teachers and tolerance: Discriminating diversity dispositions. The Teacher Educator, 42(1), 30-62.

Leonardo, Z. (2009). The color of supremacy: Beyond the discourse of "white privilege." In E. Taylor; D. Gillborn, \& G. Ladson-Billings (Eds.), Foundations of Critical Race theory in education (pp. 261-276). New York, NY: Routledge.

Lensmire, A. (2012). White urban teachers: Stories of fear, violence, and desire. London, United Kingdom: R\&L Education.

McDonough, K. (2009). Pathways to critical consciousness: A first-year teacher's engagements with issues of race and equity. Journal of Teacher Education, 60(5), 528-537.

Mclntosh, P. (1988). White privilege: Unpacking the invisible knapsack. Retrieved from https://nationalseedproject.org/white-privilege-unpacking-the-invisible -knapsack

Milner, H. R. (2008). Critical race theory and interest convergence as analytic tools in teacher education policies and practices. Journal of Teacher Education, 59(4), 332-346.

Modica, M. (2012). Constructions of race among religiously conservative college students. Multicultural Perspectives, 14(1), 38-43.

Neuendorf, K. A. (2016). The content analysis guidebook. London, United Kingdom: Sage.

Picower, B. (2009). The unexamined whiteness of teaching: How white teachers maintain and enact dominant racial ideologies. Race, Ethnicity and Education, 12(2), 197-215.

Pimentel, C. (2010). Critical race talk in teacher education through movie analysis: From Stand and Deliver to Freedom Writers. Multicultural Education, 17(3), 51-56.

Sleeter, C. E. (1995). An analysis of the critiques of multicultural education. In Banks, J. A. \& McGee Banks, C.A. (Eds.), Handbook of research on multicultural education. New York, NY: Macmillan. 
Solòrzano, D. G., \& Yosso, T. J. (2001). From racial stereotyping and deficitdiscourse: Toward a critical race theory in teacher education. Multicultural Education, 9(1), 2-8.

Taylor, E. (2009). The foundations of critical race theory in education: An introduction. In E. Taylor; D. Gillborn \& G. Ladson-Billings (Eds.), Foundations of Critical Race Theory in education (pp. 1-16). New York, NY: Routledge.

Tenenbaum, H. R., \& Ruck, M. D. (2007). Are teachers' expectations different for racial minority than for European American students? A meta-analysis. Journal of Educational Psychology, 99(2), 253-273.

VanDeventer Iverson, S. (2007). Camouflaging power and privilege: A critical race analysis of university diversity policies. Educational Administration Quarterly, 43(5), 586-611.

Virtanen, S. V., \& Huddy, L. (1998). Old-fashioned racism and new forms of racial prejudice. The Journal of Politics, 60(2), 311-332.

Watson, D. (2012). Norming suburban: How teachers talk about race without using race words. Urban Education, 47(5), 983-1004.

Young, E. Y. (2011). The four personae of racism: Educators' (mis)understanding of individual vs. systemic racism. Urban Education, 46(6), 1433-1460.

\section{Author Contact}

Melissa Beth Wilson: M.Wilson@leedstrinity.ac.uk

Leeds Trinity University, Brownberrie Ln, Horsforth, Leeds LS18 5HD, UK

Tracey Kumar: tracey.kumar@selu.edu

Southeastern Louisiana University, 500 W University Ave, Hammond, LA 70402 